\title{
Perancangan Sistem Informasi Bengkel Motor X
}

\author{
Anisa Prilia Dewi* \\ Prodi Akuntansi, Fakultas Ekonomi dan Bisnis, Universitas Islam \\ Bandung, Indonesia. \\ *anisapriliad@gmail.com
}

\begin{abstract}
This study aims to study the information system implemented by the X workshop. X workshop is a business engaged in two-wheeled vehicle repair services. This research begins by identifying the problems that occur in the X Workshop information system. The problems found include: there is no clear, documented and adequate organization, then there is no clear and written system that results in duplicate tasks and functions, the documents used are insufficient and very minimal information, as well as reports for every business transaction that occurs. So the owner can't control it. The design of this information system helps assist the workshop in carrying out its operations by providing solutions to problems that occur. The new information system is expected to provide convenience in transactions, improve supervisory functions and provide added value for workshops. The research method used is descriptive analysis method. The author also uses the FAST (Framework for the Application of System Technique) method through the JAD (Joint Application Development) approach. The result of this research is the creation of a new information system for $\mathrm{X}$ with system coverage covering sales information systems, purchasing information systems, inventory information systems, payroll information systems and financial information systems.
\end{abstract}

Keywords: Information systems. Workshop

Abstrak. Penelitian ini bertujuan untuk mempelajari system informasi yang diterapkan oleh X bengkel. Bengkel X merupakan usaha yang bergerak di bidang pelayanan jasa reparasi kendaraan roda dua. Penelitian ini dimulai dengan mengidentifikasi permasalahan-permasalahan yang terjadi pada sistem informasi Bengkel X. Adapun permasalahan yang ditemukan diantaranya adalah : tidak ada struktur organisasi yang jelas, terdokumentasi dan memadai selanjutnya tidak adanya uraian tugas yang jelas dan tertulis sehingga mengakibatkan terjadinya rangkap tugas dan fungsi, dokumen yang digunakan tidak memadai dan sangat minim informasi, serta tidak dibuatnya laporan untuk setiap transaksi bisnis yang terjadi sehingga pemilik tidak dapat melakukan pengawasan. Perancangan system informasi ini dimaksudkan untuk membantu bengkel dalam menjalankan operasionalnya dengan cara memberikan solusi atas permasalahan yang terjadi. Diharapkan system informasi yang baru dapat memberikan kemudahan dalam bertransaksi, meningkatkan fungsi pengawasan dan memberikan nilai tambah bagi bengkel. Metode penelitian yang digunakan adalah metode analisis deskriptif. Penulis juga menggunakan metode FAST (Framework for the Application of System Technique) melalui pendekatan JAD (Joint Application Development). Hasil dari penelitian ini adalah dibuatkannya system informasi yang baru bagi $\mathrm{X}$ bengkel dengan cakupan system meliputi system informasi penjualan, system informasi pembelian, system informasi persediaan, system informasi penggajian serta sistem informasi keuangan.

Kata Kunci: Bengkel, Sistem Informasi. 


\section{A. Pendahuluan}

Revolusi digital telah mempengaruhi perspektif manusia dalam berbagai aspek kehidupan. Salah satu teknologi yang menjadi faktor penting dalam suatu bisnis adalah teknologi informasi. Whitten dan Bentley (1) menyatakan bahwa "banyak organisasi menganggap sistem informasi sebagai hal yang penting untuk kemampuan mereka dalam bersaing atau untuk mendapatkan keuntungan bersaing". Senada dengan pernyataan dari Zapir, Nurhayati \& Halimatusadiah (2) bahwa penggunaan teknologi informasi dapat mempermudah aktivitas operasional bisnis sehingga setiap unitnya dapat menyelesaikan tugas dengan cepat dan mudah

Menurut Laudon \& Laudon (3), penggunaan teknologi informasi termasuk dalam serangkaian kegiatan yang dapat memberi nilai tambah pada setiap informasi yang diperoleh, diubah dan didistribusikan sehingga dapat meningkatkan pengambilan keputusan, memperbarui kinerja organisasi dan meningkatkan profit perusahaan. Saat ini hampir seluruh sector bisnis memanfaatkan teknologi informasi secara maksimal guna meningkatkan kualitasnya tidak terkecuali sector pelayanan jasa seperti bengkel. Bengkel merupakan salah satu usaha yang bergerak di sektor pelayanan jasa yaitu melayani jasa perbaikan dan perawatan kendaraaan bermotor. Selain memberikan jasa, bengkel juga melakukan transaksi penjualan sparepart. Eksistensi bisnis bengkel berkembang secara pesat seiring dengan perubahan gaya hidup masyarakat yang menjadikan kendaraan sebagai kebutuhan primernya. Perkembangan aktivitas bisnis membuat transaksi yang terjadi di bengkel semakin berkembang secara jumlah dan jenis layanan yang disesuaikan dengan kebutuhan pelanggan. Oleh karena itu, dibutuhkan sistem informasi yang dapat mencakup seluruh aktifitas bisnis sehingga seluruh aktifitas dapat dicatat secara akurat dan menghindari kemungkinan terjadinya kecurangan..

Berdasarkan uraian diatas, penulis tertarik untuk merancang sistem informasi yang berkualitas untuk mendukung operasional Bengkel X. X bengkel motor terletak di Kampung Sondol, RT 02 RW 02, Kelurahan Kutabumi, Kecamatan Pasar Kemis, Kabupaten Tangerang, Banten.

Dalam melaksanakan kegiatan operasionalnya, Bengkel X dihadapkan pada berbagai kendala, seperti memiliki struktur organisasi yang tidak lengkap dan belum ada job description yang jelas dan tertulis sehingga terjadi rangkap tugas dan fungsi dari masing-masing personil bengkel. Selain melakukan pengawasan kegiatan operasional bengkel, pemilik juga bertanggungjawab atas urusan keuangan bengkel. Namun aktivitas pengelolaan keuangan ini., tidak didokumentasikan secara memadai

Kendala lain yang dihadapi adalah terkait dengan pengelolaan persediaan sparepart. Untuk mengetahui perkiraan persediaan yang ada di gudang, biasanya pemilik menanyakan kepada kasir namun informasi dari kasir merupakan perkiraan saja sehingga jenis sparepart yang harus dibeli dan jumlahnya menjadi bias. Selain itu, pada saat penerimaan atau pengeluaran spare part dari gudang, kasir tidak melakukan pencatatan sehingga peredaran persediaan (inventory turnover) sulit dikendalikan.

Selain itu nota penjualan yang dibuat hanya satu rangkap untuk konsumen saja tanpa mengarsipkannya untuk kepentingan bengkel. Hal ini sangat memudahkan kasir untuk memanipulasi jumlah penjualan dan pendapatan penjualan yang didapatkan setiap harinya. Kendala selanjutnya ditemukan dalam prosedur penggajian dimana catatan utang yang dikelola oleh pemilik dicatat secara sederhana dan mudah rusak. Pembayaran gaji pendapatan jasa harian kepada teknisi dilakukan oleh kasir tanpa adanya keterlibatan dari pemilik sehingga rentan terjadinya kecurangan. Pembayaran gaji bulanan juga dilakukan tanpa menyertakan slip gaji untuk setiap pegawai.

Berdasarkan permasalahan-permasalahan yang telah diuraikan, maka penulis akan membuat usulan perancangan sistem informasi yang baru bagi Bengkel $\mathrm{X}$ yang mencakup sistem informasi penjualan, sistem informasi pembelian, sistem informasi persediaan, sistem informasi penggajian dan sistem informasi keuangan yang memadai guna untuk mendukung pelaksanaan kegiatan operasional. Hal ini akan tertuang ke dalam penelitian yang berjudul "PERANCANGAN SISTEM INFORMASI BENGKEL MOTOR X".

Berdasarkan latar belakang yang telah diuraikan, maka masalah-masalah yang dapat diidentifikasikan adalah sebagai berikut : 
1. Bagaimana system informasi yang sedang diterapkan oleh Bengkel $X$ dan apa saja permasalahan-permasalahan yang terjadi ?

2. Bagaimana model system informasi yang diusulkan untuk mengimplementasikan di Bengkel X?

Selanjutnya tujuan dalam penelitian ini diuraikan dalam pokok-pokok sebagai berikut :

1. Untuk mengetahui system informasi yang sedang diterapkan oleh Bengkel X dan mengidentifikasi permasalahan-permasalahan yang terjadi.

2. Untuk memahami dan membuat model perancangan system informasi yang sesuai untuk diterapkan di Bengkel X motor

\section{B. Metodologi Penelitian}

Dalam melakukan perancangan sistem informasi ini, terdapat beberapa metode yang dilakukan oleh penulis antara lain metode analisis deskriptif melalui Framework for The Application of System Technique Methodology (Metode FAST). Menurut Sekaran \& Bougie (4), "penelitian deskriptif merupakan penelitian yang bertujuan untuk mengetahui, memahami dan menggambarkan karakteristik dari manusia, kejadian atau situasi yang menjadi focus penelitian”. Selanjutnya, metode FAST merupakan salah satu metode pengembangan sistem yang merinci setiap proses pengembangan sistem kedalam beberapa tahapan, disetiap tahapan terdiri atas beberapa fase dan di setiap fase terdiri atas beberapa aktivitas.

Selain itu, penulis juga menggunakan pendekatan Joint Appication Development (JAD). $J A D$ merupakan pendekatan yang dilakukan untuk menjalin kerja sama yang harmonis antara system user, system owner dan system developer dalam memberikan informasi mengenai kebutuhan masing-masing pihak terhadap sistem yang sedang dikembangkan agar menghasilkan sistem yang mampu memenuhi kebutuhan setiap pihak.

Pengumpulan data dilakukan dengan menggabungkan beberapa metode pengumpulan data seperti wawancara, observasi dan dokumentansi. Adapun instrument penelitian yang digunakan berupa building block system informasi, pedoman wawancara, alat perekam dan kamera.

\section{Hasil Penelitian dan Pembahasan}

\section{Sistem Informasi Pembelian yang Diusulkan}

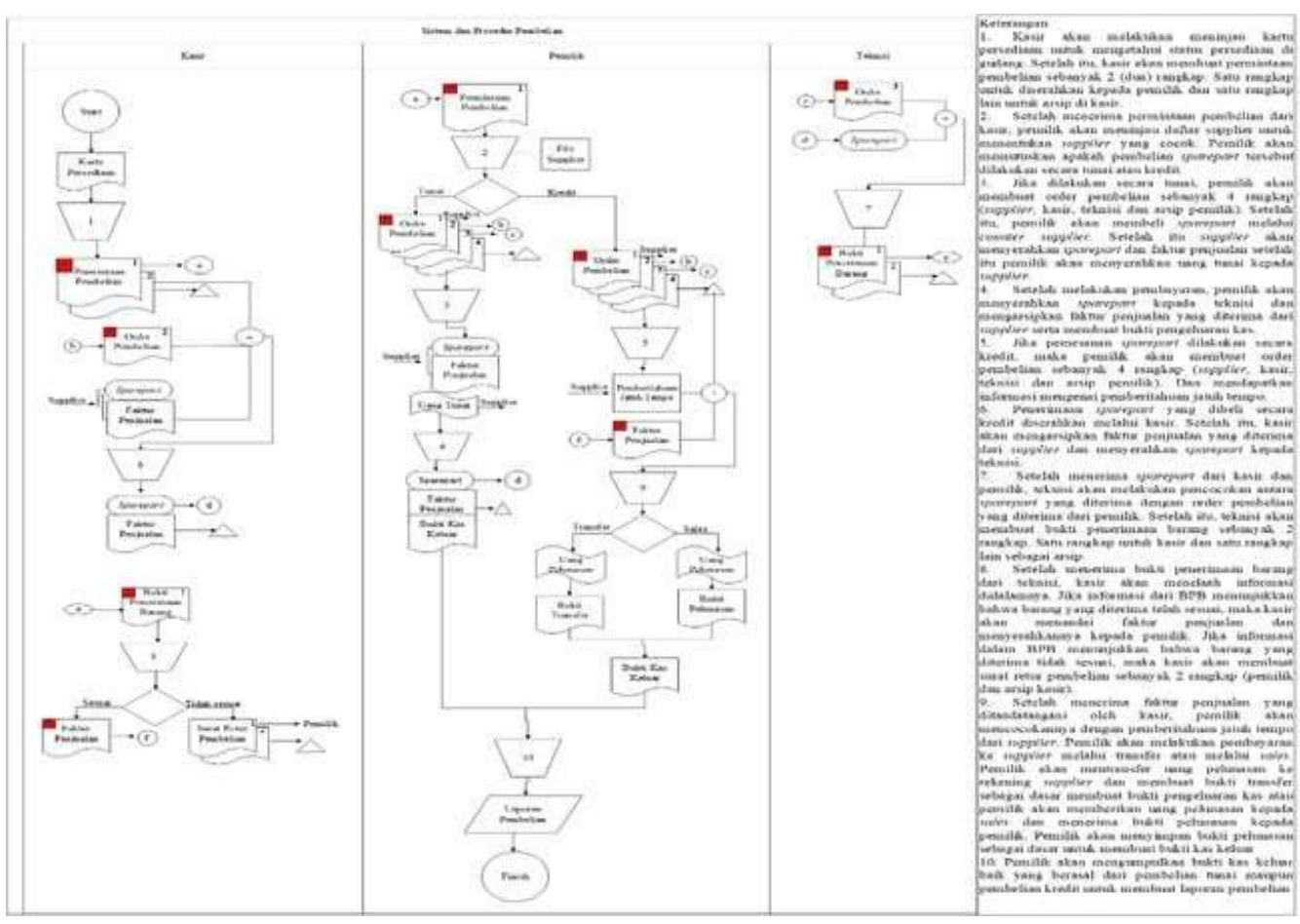

Gambar 1. Sistem Informasi Pembelian yang Diusulkan 
Sistem Informasi Penjualan yang Diusulkan

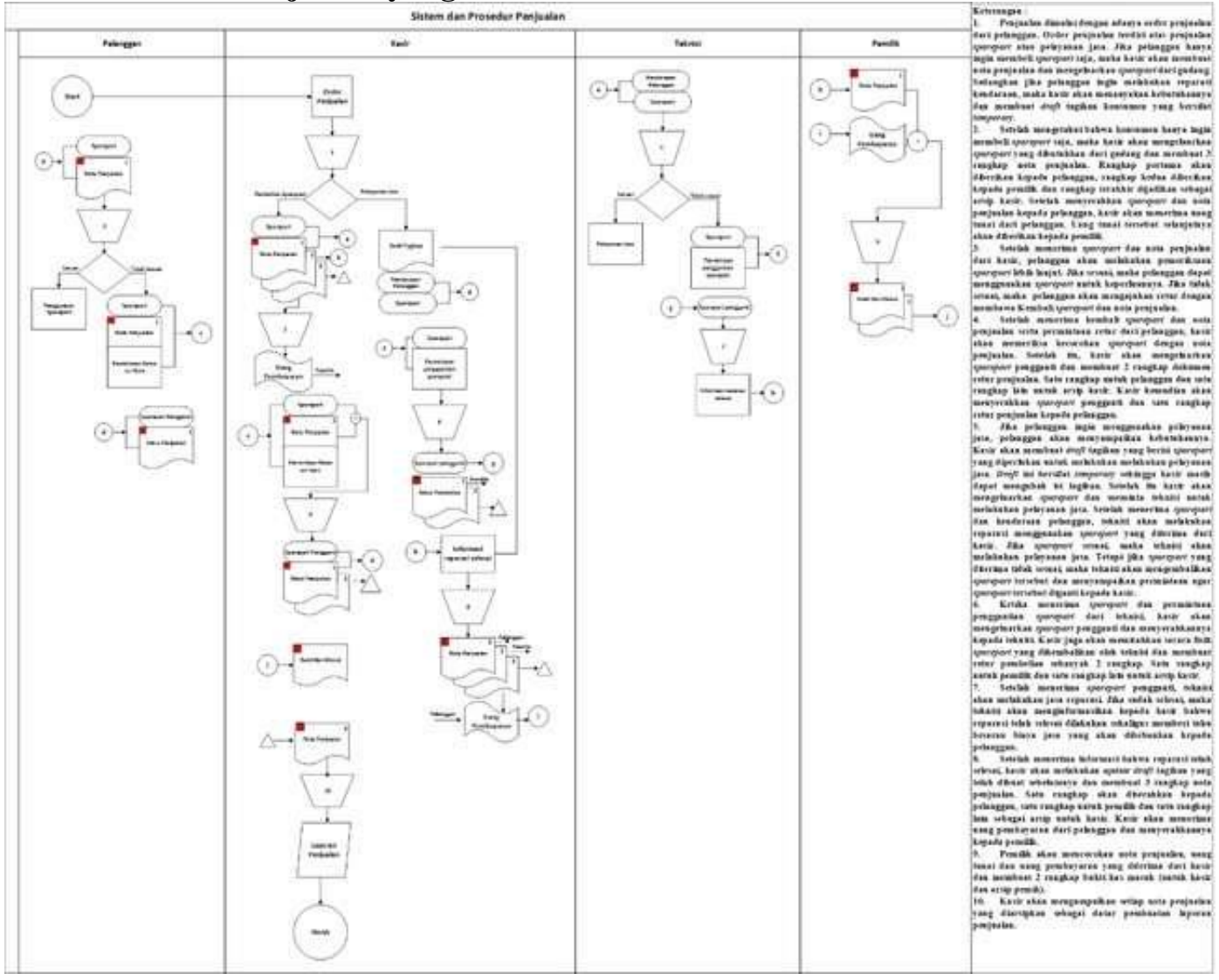

Gambar 2. Sistem Informasi Penjualan yang Diusulkan

\section{Sistem Informasi Persediaan yang Diusulkan}

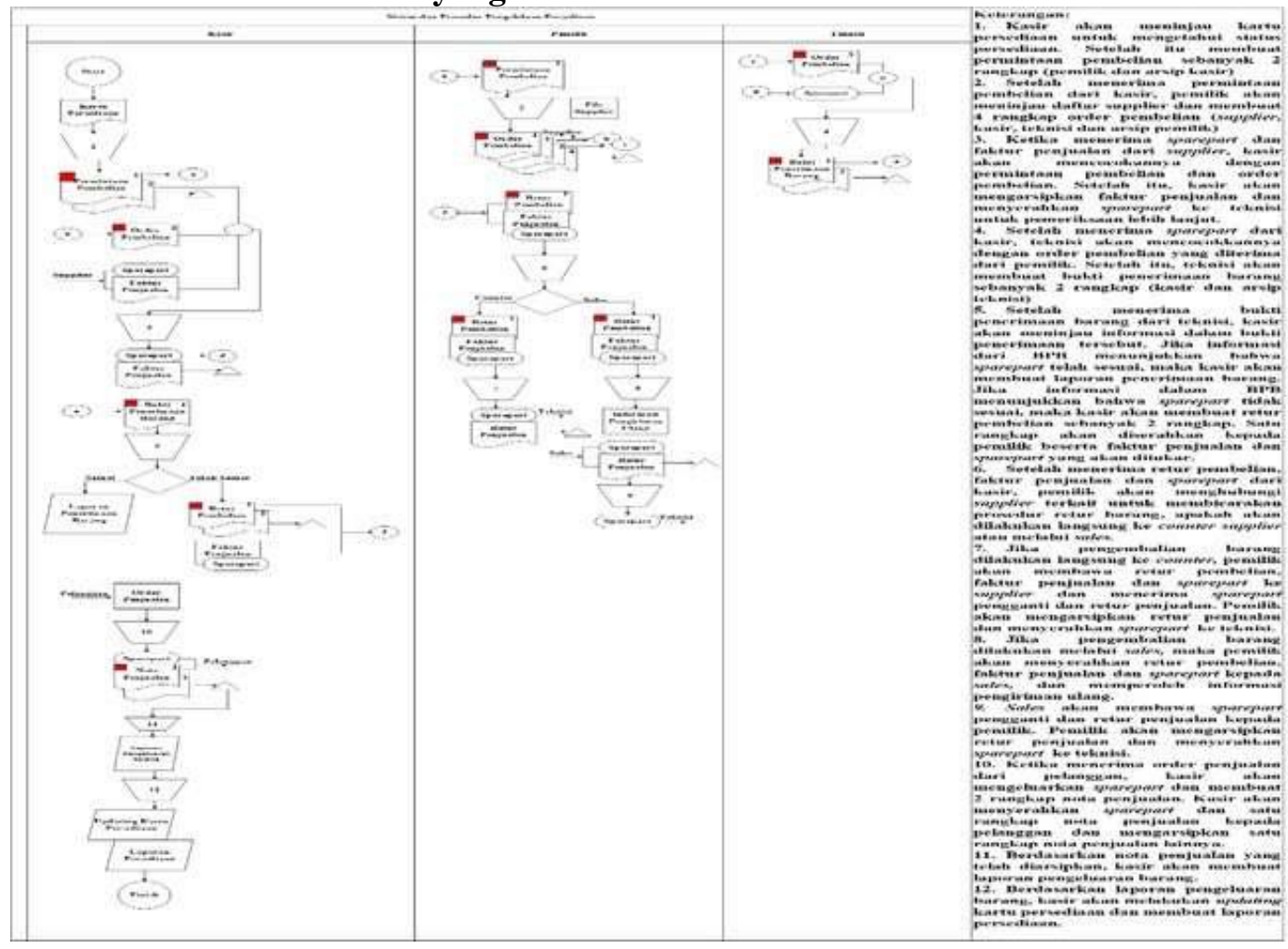

Gambar 3. Sistem Informasi Persediaan yang Diusulkan 


\section{Sistem Informasi Penggajian yang Diusulkan}

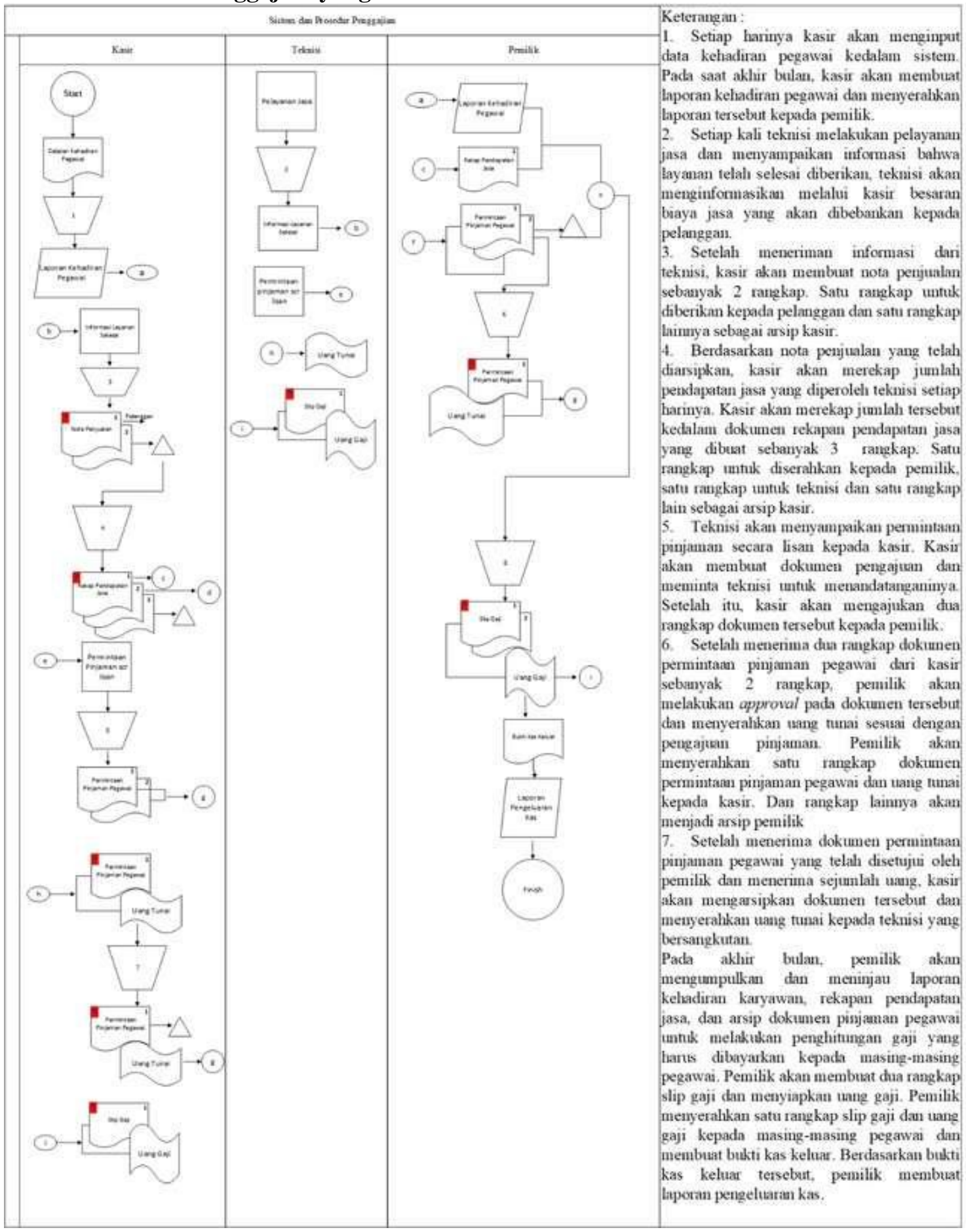

Gambar 4. Sistem Informasi Penggajian yang Diusulkan 
Sistem Informasi Keuangan yang Diusulkan

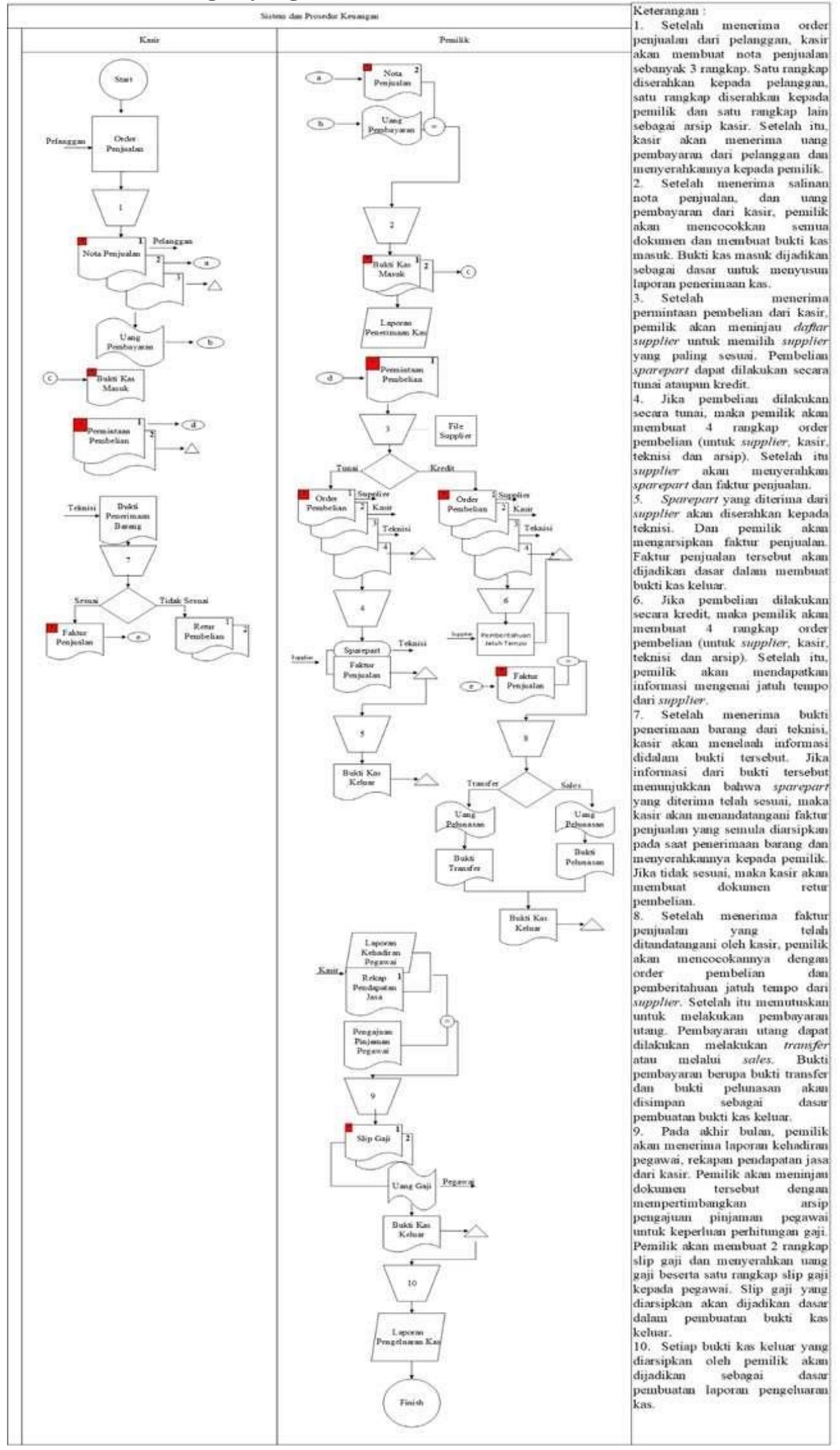

Gambar 5. Sistem Informasi Keuangan yang Diusulkan

JRA is licensed under Creative Commons Attribution- 
Tabel dibawah ini menguraikan perbedaaan system yang saat ini diterapkan dan system yang diusulkan :

\begin{tabular}{|c|c|c|c|}
\hline No. & $\begin{array}{l}\text { Sistem yang sedang } \\
\text { diterapkan }\end{array}$ & Sistem yang diusulkan & Alasan \\
\hline \multicolumn{4}{|c|}{ Model Permasalahan Umum Pada Sistem Informasi yang Sedang Diterapkan } \\
\hline 1. & $\begin{array}{lr}\text { Struktur } & \text { organisasi } \\
\text { Bengkel } \mathrm{X} \text { tidak } \\
\text { lengkap sehingga } \\
\text { belum mencantumkan } \\
\text { kepala teknisi }\end{array}$ & $\begin{array}{lr}\text { Dibuatkan } & \text { struktur } \\
\text { organisasi } & \text { yang } \\
\text { lengkap } & \text { daru, } \\
\text { terdokumentasi dengan } \\
\text { menambahkan kepala } \\
\text { teknisi }\end{array}$ & $\begin{array}{l}\text { Struktur organisasi harus diperbarui } \\
\text { agar Bengkel X memiliki struktur } \\
\text { organisasi yang lengkap }\end{array}$ \\
\hline 2. & $\begin{array}{l}\text { Tidak ada tugas dan } \\
\text { fungsi yang tetap } \\
\text { untuk setiap pihak } \\
\text { dalam Bengkel X }\end{array}$ & $\begin{array}{lr}\text { Dibuatkan } & \text { job } \\
\text { description } & \text { yang } \\
\text { lengkap, jelas } & \text { dan } \\
\text { tertulis } & \\
\end{array}$ & $\begin{array}{l}\text { Job description diperlukan agar } \\
\text { setiap pihak dalam Bengkel } \mathrm{X} \text { dapat } \\
\text { menjalankan tugas, fungsi dan } \\
\text { tanggungjawabnya. }\end{array}$ \\
\hline 3. & $\begin{array}{l}\text { Pemilik dan kasir } \\
\text { bertanggungjawab } \\
\text { untuk melakukan } \\
\text { penerimaan sparepart } \\
\text { dari teknisi tanpa ada } \\
\text { pemeriksaan lebih } \\
\text { lanjut. }\end{array}$ & $\begin{array}{lr}\text { Fungsi penerimaan dan } \\
\text { pengecekan } & \text { sparepart } \\
\text { dialihkan } & \text { kepada } \\
\text { teknisi. } & \end{array}$ & $\begin{array}{l}\text { Fungsi penerimaan dan pengecekan } \\
\text { sparepart harus dilakukan oleh } \\
\text { seseorang yang memiliki } \\
\text { pengetahuan yang mumpuni terkait } \\
\text { kualifikasi sparepart sehingga } \\
\text { Bengkel X memperoleh sparepart } \\
\text { yang berkualitas. }\end{array}$ \\
\hline \multicolumn{4}{|c|}{ Model Permasalahan Khusus Pada Sistem Informasi Pembelian } \\
\hline 1. & $\begin{array}{l}\text { Tidak ada surat } \\
\text { permintaan pembelian }\end{array}$ & $\begin{array}{l}\text { Dibuatkan surat } \\
\text { permintaan pembelian } \\
\text { yang memadai }\end{array}$ & $\begin{array}{l}\text { Bengkel X harus memiliki surat } \\
\text { permintaan pembelian sehingga } \\
\text { pemilik mendapatkan informasi yang } \\
\text { jelas terkait sparepart apa saja yang } \\
\text { akan dibeli }\end{array}$ \\
\hline 2. & $\begin{array}{l}\text { Tidak ada dokumen } \\
\text { order pembelian }\end{array}$ & $\begin{array}{l}\text { Dibuatkan dokumen } \\
\text { order pembelian yang } \\
\text { memadai }\end{array}$ & $\begin{array}{l}\text { Bengkel X perlu memiliki order } \\
\text { pembelian sehingga meminimalisir } \\
\text { kesalahan pada saat melakukan } \\
\text { pemesanan sparepart }\end{array}$ \\
\hline 3. & $\begin{array}{l}\text { Tidak membuat daftar } \\
\text { supplier }\end{array}$ & $\begin{array}{l}\text { Dibuatkan daftar } \\
\text { supplier yang lengkap }\end{array}$ & $\begin{array}{l}\text { Daftar supplier dapat memudahkan } \\
\text { pemilik untuk melakukan } \\
\text { pemesanan. Selain itu, dengan } \\
\text { memilih supplier yang sudah } \\
\text { bermitra dengan } \\
\begin{array}{l}\text { bengkel, } \\
\text { memungkinkan }\end{array} \\
\text { mendapatkan harga yang lebih } \\
\text { murah. }\end{array}$ \\
\hline 4. & $\begin{array}{l}\text { Tidak ada surat retur } \\
\text { pembelian }\end{array}$ & 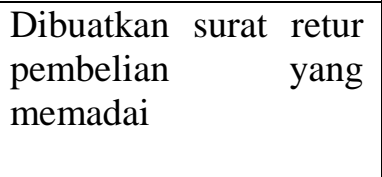 & $\begin{array}{l}\text { Bengkel X perlu memiliki surat retur } \\
\text { pembelian sehingga sparepart yang } \\
\text { akan diretur dapat didokumentasikan } \\
\text { secara memadai }\end{array}$ \\
\hline 5. & $\begin{array}{l}\text { Setiap dokumen yang } \\
\text { digunakan pada sistem } \\
\text { pembelian tidak } \\
\text { diotorisasi }\end{array}$ & $\begin{array}{l}\text { Setiap dokumen } \text { yang } \\
\text { digunakan pada sistem } \\
\text { pembelian } r \text { sudah } \\
\text { diotorisasi oleh } \\
\text { terkaihak }\end{array}$ & $\begin{array}{l}\text { Dokumen yang digunakan harus } \\
\text { diotorisasi } \text { sehingga dokumen } \\
\text { tersebut dikatakan sah. }\end{array}$ \\
\hline 6. & $\begin{array}{l}\text { Tidak ada laporan } \\
\text { pembelian yang dibuat }\end{array}$ & $\begin{array}{lr}\text { Dibuatkan } & \text { laporan } \\
\text { pembelian } & \text { secara } \\
\text { periodic yang lengkap } \\
\text { dan memadai }\end{array}$ & \begin{tabular}{lr}
\multicolumn{3}{l}{ Bengkel X } & harus memiliki laporan \\
pembelian sehingga aktivitas \\
pembelian & dapat \\
dipertanggungjawabkan.
\end{tabular} \\
\hline
\end{tabular}




\begin{tabular}{|c|c|c|c|}
\hline \multicolumn{4}{|c|}{ Model Permasalahan Khusus Pada Sistem Informasi Penjualan } \\
\hline 1. & $\begin{array}{l}\text { Nota penjualan yang } \\
\text { tersedia tidak lengkap } \\
\text { dan memadai }\end{array}$ & $\begin{array}{lr}\text { Dibuatkan } & \text { nota } \\
\text { penjualan } & \text { yang } \\
\text { lengkap dan memadai }\end{array}$ & $\begin{array}{l}\text { Bengkel } X \text { harus memiliki nota } \\
\text { penjualan yang memadai agar } \\
\text { informasi mengenai penjualan } \\
\text { menjadi lengkap dan jelas }\end{array}$ \\
\hline 2. & $\begin{array}{l}\text { Tidak ada } \text { otorisasi } \\
\text { pada nota penjualan } \\
\text { yang saat ini } \\
\text { digunakan }\end{array}$ & $\begin{array}{l}\text { Kasir sebagai pihak } \\
\text { yang } \\
\text { bertanggungjawab atas } \\
\text { aktivitas penjualan } \\
\text { harus mengotorisasi } \\
\text { setiap nota penjualan } \\
\text { yang dikeluarkan }\end{array}$ & $\begin{array}{l}\text { Nota penjualan harus diotorisasi agar } \\
\text { dokumen tersebut dapat diakui } \\
\text { sebagai bukti transaksi yang sah }\end{array}$ \\
\hline 3. & $\begin{array}{l}\text { Bengkel saat ini tidak } \\
\text { memiliki arsip nota } \\
\text { penjualan }\end{array}$ & $\begin{array}{lr}\text { Menambahkan } & \\
\text { prosedur } & \text { untuk } \\
\text { mengarsipkan } & \text { setiap } \\
\text { nota penjualan } & \text { yang } \\
\text { dibuat } & \\
\end{array}$ & $\begin{array}{l}\text { Bengkel X perlu memiliki arsip nota } \\
\text { penjualan agar informasi mengenai } \\
\text { penjualan } \\
\text { dipertanggungjawabkan } \\
\text { pemilik }\end{array}$ \\
\hline 4. & $\begin{array}{l}\text { Tidak ada surat retur } \\
\text { penjualan }\end{array}$ & 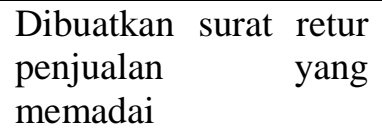 & $\begin{array}{l}\text { Bengkel X perlu membuat surat retur } \\
\text { penjualan agar informasi mengenai } \\
\text { sparepart yang diretur oleh pembeli. }\end{array}$ \\
\hline 5. & $\begin{array}{l}\text { Rekapan pendapatan } \\
\text { yang dibuat saat ini } \\
\text { sangat tidak memadai }\end{array}$ & $\begin{array}{lr}\text { Dibuatkan } & \text { laporan } \\
\text { penjualan } & \text { yang } \\
\text { memadai } & \end{array}$ & $\begin{array}{l}\text { Laporan penjualan perlu dibuat agar } \\
\text { pemilik dapat mengetahui secara } \\
\text { pasti jumlah penjualan yang telah } \\
\text { dilakukan setiap periodenya }\end{array}$ \\
\hline \multicolumn{4}{|c|}{ Model Permasalahan Khusus Pada Sistem Informasi Persediaan } \\
\hline 1. & $\begin{array}{lrr}\begin{array}{l}\text { Bengkel } \\
\text { membuat }\end{array} & \text { tidak } \\
\text { bukti } \\
\text { penerimaan } & \text { sparepart }\end{array}$ & $\begin{array}{l}\text { Dibuatkan bukti } \\
\text { penerimaan sparepart } \\
\text { yang memadai }\end{array}$ & $\begin{array}{l}\text { Dokumen ini diperlukan agar } \\
\text { informasi mengenai penerimaan } \\
\text { sparepart didokumentasikan secara } \\
\text { memadai }\end{array}$ \\
\hline 2. & $\begin{array}{lrr}\text { Bengkel } \quad X \quad \text { tidak } \\
\text { memiliki } & \text { laporan } \\
\text { penerimaan } & \text { barang }\end{array}$ & $\begin{array}{lr}\text { Dibuatkan } & \text { laporan } \\
\text { penerimaan } & \text { barang } \\
\text { yang memadai } & \end{array}$ & $\begin{array}{lrr}\text { Laporan penerimaan } & \text { sparepart } \\
\text { diperlukan sebagai } & \text { bentuk } \\
\text { pertanggungjawaban atas } & \text { aktivitas } \\
\text { penerimaan barang } & \end{array}$ \\
\hline 3. & $\begin{array}{lrr}\text { Bengkel } & \text { X } r \text { tidak } \\
\text { memiliki } & \text { laporan } \\
\text { pengeluaran } & \text { sparepart }\end{array}$ & $\begin{array}{l}\text { Dibuatkan laporan } \\
\text { pengeluaran sparepart } \\
\text { yang memadai }\end{array}$ & $\begin{array}{lr}\text { Laporan pengeluaran } & \text { sparepart } \\
\text { diperlukan sebagai } & \text { bentuk } \\
\text { pertanggungjawaban } & \text { atas } \\
\text { pengeluaran barang serta dokumen } \\
\text { pendukung atas aktivitas penjualan }\end{array}$ \\
\hline 4. & $\begin{array}{l}\text { Tidak ada kartu } \\
\text { persediaan yang dapat } \\
\text { menunjang aktivitas } \\
\text { pengelolaan } \\
\text { persediaan } \\
\end{array}$ & $\begin{array}{l}\text { Dibuatkan } \\
\text { persediaan } \\
\text { memadai }\end{array}$ & $\begin{array}{l}\text { Kartu persediaan diperlukan untuk } \\
\text { mendokumentasikan status } \\
\text { persediaan yang tersedia di gudang. }\end{array}$ \\
\hline 5. & $\begin{array}{lrr}\text { Bengkel } & X & \text { tidak } \\
\text { memiliki } & & \text { laporan } \\
\text { persediaan } & \end{array}$ & $\begin{array}{lr}\text { Dibuatkan } & \text { laporan } \\
\text { persediaan } & \text { yang } \\
\text { memadai } & \\
\end{array}$ & $\begin{array}{l}\text { Laporan persediaan diperlukan untuk } \\
\text { mengetahui jumlah persediaan pada } \\
\text { suatu periode }\end{array}$ \\
\hline \multicolumn{4}{|c|}{ Model Permasalahan Khusus Pada Sistem Informasi Penggajian } \\
\hline 1. & $\begin{array}{lrr}\text { Bengkel } & \text { X } & \text { tidak } \\
\text { mencatat } & \text { kehadiran } \\
\text { pegawai } & \text { setiap } \\
\text { harinya. } & & \end{array}$ & $\begin{array}{l}\text { Dibuatkan catatan } \\
\text { kehadiran pegawai } \\
\text { yang dapat diisi oleh } \\
\text { kasir setiap harinya. }\end{array}$ & 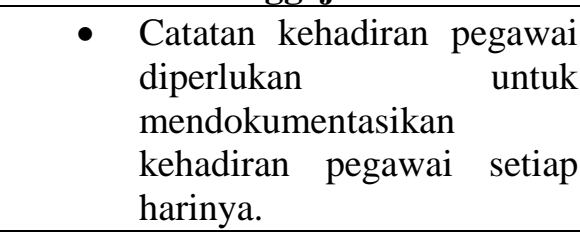 \\
\hline
\end{tabular}




\begin{tabular}{|c|c|c|c|}
\hline & & & $\begin{array}{l}\text { Selain sebagai dasar } \\
\text { penyusunan laporan } \\
\text { kehadiran, catatan kehadiran } \\
\text { ini dapat membantu pemilik } \\
\text { meninjau kinerja dari } \\
\text { masing-masing pegawai. }\end{array}$ \\
\hline 2. & $\begin{array}{l}\text { Bengkel } \mathrm{X} \text { tidak } \\
\text { membuat laporan } \\
\text { kehadiran pegawai }\end{array}$ & $\begin{array}{lr}\text { Dibuatkan laporan } \\
\text { kehadiran pegawai } \\
\text { yang memadai }\end{array}$ & $\begin{array}{l}\text { Laporan kehadiran pegawai } \\
\text { diperlukan sebagai dasar perhitungan } \\
\text { gaji yang akan dibayarkan setiap } \\
\text { bulannya. }\end{array}$ \\
\hline 3. & $\begin{array}{l}\text { Bengkel } X \quad \text { tidak } \\
\text { membuat } \\
\text { pendapatan jasa }\end{array}$ & $\begin{array}{l}\text { Dibuatkan rekapan } \\
\text { pendapatan jasa untuk } \\
\text { setiap teknisi }\end{array}$ & $\begin{array}{l}\text { - Rekapan pendapatan jasa } \\
\text { diperlukan sebagai bukti } \\
\text { untuk menghitung } \\
\text { pendapatan jasa yang } \\
\text { diperoleh setiap teknisi } \\
\text { perbulannya. } \\
\text { - } \\
\text { Rekapan pendapatan jasa } \\
\text { juga dapat digunakan } \\
\text { pemilik untuk mengevaluasi } \\
\text { kinerja teknisi }\end{array}$ \\
\hline 4. & $\begin{array}{lr}\text { Pengajuan pinjaman } \\
\text { pegawai tidak } \\
\text { didokumentasikan } \\
\text { dengan baik }\end{array}$ & $\begin{array}{ll}\text { Dibuatkan } & \text { dokumen } \\
\text { permintaan } & \text { pinjaman } \\
\text { pegawai } & \end{array}$ & $\begin{array}{l}\text { Dokumen permintaan pinjaman } \\
\text { pegawai diperlukan untuk } \\
\text { mengetahui jumlah pinjaman yang } \\
\text { diajukan oleh setiap pegawai }\end{array}$ \\
\hline 5. & $\begin{array}{l}\text { Bengkel } X \text { tidak } \\
\text { membuat slip gaji }\end{array}$ & $\begin{array}{l}\text { Dibuatkan slip gaji } \\
\text { yang memadai }\end{array}$ & $\begin{array}{l}\text { Slip gaji perlu dibuat sebagai } \\
\text { dokumentansi rincian perhitungan } \\
\text { gaji pegawai setiap bulannya. }\end{array}$ \\
\hline \multicolumn{4}{|c|}{ Model Permasalahan Khusus Pada Sistem Informasi Keuangan } \\
\hline 1. & $\begin{array}{lr}\text { Pemilik } & \text { tidak } \\
\text { membuat } & \text { bukti kas } \\
\text { masuk } & \end{array}$ & $\begin{array}{l}\text { Dibuatkan dokumen } \\
\text { bukti kas masuk yang } \\
\text { memadai }\end{array}$ & $\begin{array}{l}\text { Pemilik perlu untuk membuat bukti } \\
\text { kas masuk agar setiap penerimaan } \\
\text { kas dapat dicatat secara memadai }\end{array}$ \\
\hline 2. & 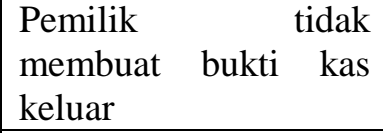 & $\begin{array}{l}\text { Dibuatkan dokumen } \\
\text { bukti kas keluar yang } \\
\text { memadai }\end{array}$ & $\begin{array}{l}\text { Pemilik perlu untuk membuat bukti } \\
\text { kas keluar agar setiap pengeluaran } \\
\text { kas dapat dicatat secara memadai }\end{array}$ \\
\hline 3. & $\begin{array}{lr}\text { Pemilik } r \text { tidak } \\
\text { membuat laporan } \\
\text { penerimaan kas }\end{array}$ & $\begin{array}{l}\text { Dibuatkan laporan } \\
\text { penerimaan kas yang } \\
\text { memadai }\end{array}$ & $\begin{array}{l}\text { Laporan penerimaan kas digunakan } \\
\text { untuk mengetahui jumlah } \\
\text { penerimaan kas setiap periodenya }\end{array}$ \\
\hline 4. & $\begin{array}{l}\text { Pemilik tidak } \\
\text { membuat laporan } \\
\text { pengeluaran kas }\end{array}$ & $\begin{array}{l}\text { Dibuatkan laporan } \\
\text { pengeluaran kas yang } \\
\text { memadai }\end{array}$ & $\begin{array}{ll}\text { - } & \text { Laporan pengeluaran kas } \\
\text { diperlukan } & \text { untuk } \\
\text { memudahkan } & \text { pemilik } \\
\text { mengetahui } & \text { jumlah } \\
\text { pengeluaran kas yang } & \text { dilakukan setiap periodenya } \\
\text { - } & \text { Laporan ini juga } \\
\text { memudahkan pemilik } & \text { menelurusi penggunaan kas } \\
& \text { bengkel setiap periode }\end{array}$ \\
\hline
\end{tabular}

\section{Kesimpulan}

Berdasarkan penelitian yang telah dilakukan pada Bengkel $\mathrm{X}$, maka penulis dapat menyimpulkan bahwa :

Sistem informasi yang diterapkan oleh Bengkel X memiliki banyak kekurangan terutama lemahnya aspek pengendalian terhadap setiap transaksi yang dilakukan sehingga 
rentan sekali terjadinya kecurangan yang dilakukan oleh personil bengkel. Hal ini ditandai dengan banyaknya masalah yang bersifat umum maupun khusus yang berakibat terhambatnya operasional bengkel X.

Berdasarkan permasalahan-permasalahan secara umum dan khusus yang ada pada Bengkel X, maka penulis membuat rancangan sistem informasi yang baru sebagai solusi yang dapat memecahkan permasalahan-permasalahan tersebut. Penulis membuat rancangan model sistem informasi untuk sistem pembelian, sistem penjualan, sistem pengelolaan persediaan, sistem penggajian dan sistem keuangan. Penulis juga menambahkan fungsi kepala teknisi agar dapat menjadi pihak yang bertanggungjawab atas aktivitas penerimaan barang dan melakukan quality control terhadap setiap sparepart yang diterima sehingga bengkel dapat memperoleh sparepart yang sesuai dengan kebutuhan. Adapun perancangan model sistem informasi yang telah dibuat yaitu sebagai berikut :

1. Membuat struktur organisasi Bengkel $X$ secara lengkap dan tertulis

2. Menyusun job description untuk setiap personil Bengkel $X$

3. Membuat input sistem berupa : (a) permintaan pembelian; (b) order pembelian; (c) retur pembelian, (d) nota penjualan, (e) retur penjualan, (f) bukti penerimaan barang, (g) laporan kehadiran pegawai, (h) rekapan pendapatan jasa, (i) permintaan pinjaman pegawai, (j) catatan utang pegawai, (k) bukti kas masuk dan (l) bukti kas keluar.

4. Membuat proses sistem: (a) Flowchart sistem informasi dan prosedur pembelian; (b) Flowchart sistem informasi dan prosedur penjualan; (c) Flowchart sistem informasi dan prosedur persediaan; (d) Flowchart sistem informasi dan prosedur penggajian dan (e) Flowchart sistem informasi dan prosedur keuangan.

5. Membuat output sistem: (a) Laporan Pembelian; (b) Laporan Penjualan; (c) Laporan penerimaan barang; (d) Laporan pengeluaran barang; (e) Kartu persediaan; (f) Laporan persediaan ; (g) Slip gaji; (h) laporan penerimaan kas dan (i) laporan pengeluaran kas.

\section{Acknowledge}

Penulis mengucapkan terima kasih kepada semua pihak yang telah berpartisipasi dalam penelitian ini sehingga penelitian dapat diselesaikan dengan baik.

\section{Daftar Pustaka}

[1] L. Whitten, Jeffrey \& D. Bentley, Lonie. System Analysis \& Design Methods Seventh Edition. New York, USA : Mc-Graw-Hill. 2007.

[2] Zapir, Saepudin; Nurhayati, Nunung; Halimatusadiah, Elly. Perancangan Sistem Informasi Pengelolaan Barang Toko Cahaya Gemilang. Prosiding Akuntansi SPeSIA UNISBA, Vol. 4 No. 2, 760-765. 2018.

[3] Laudon, Kenneth C. \& Jane P Laudon. Sistem Informasi Manajemen: Mengelola Perusahaan Digital, Edisi 13. Terjemahan Lukki Sugito, Merry Rindy Antika, Ratna Sarawati. Jakarta: Salemba Empat. 2014.

[4] Sekaran, Uma \& Roger Bougie.Research Methods for Business: A Skill-Building Approach Seventh Edition. United Kingdom: John Willey \&Sons Ltd. 2016. 